Article

\title{
Ecosystem Management: Tomorrow's Approach to Enhancing Food Security under a Changing Climate
}

\author{
Richard Tingem Munang ${ }^{1}{ }_{*}$, Ibrahim Thiaw ${ }^{1}$ and Mike Rivington ${ }^{2}$ \\ 1 United Nations Environment Programme (UNEP), Nairobi 30197, Kenya; \\ E-Mail: Ibrahim.Thiaw @ unep.org \\ 2 The James Hutton Institute, Macaulay Drive, Craigiebuckler, Aberdeen AB15 8QH, UK; \\ E-Mail: mike.rivington@hutton.ac.uk \\ * Author to whom correspondence should be addressed; E-Mail: Richard.Munang@ unep.org; \\ Tel.: +25-4207-625-727; Fax: +25-4207-624-249.
}

Received: 25 April 2011; in revised form: 16 May 2011 / Accepted: 8 June 2011 /

Published: 28 June 2011

\begin{abstract}
This paper argues that a sustainable ecosystem management approach is vital to ensure the delivery of essential 'life support' ecosystem services and must be mainstreamed into societal conscience, political thinking and economic processes. Feeding the world at a time of climate change, environmental degradation, increasing human population and demand for finite resources requires sustainable ecosystem management and equitable governance. Ecosystem degradation undermines food production and the availability of clean water, hence threatening human health, livelihoods and ultimately societal stability. Degradation also increases the vulnerability of populations to the consequences of natural disasters and climate change impacts. With 10 million people dying from hunger each year, the linkages between ecosystems and food security are important to recognize. Though we all depend on ecosystems for our food and water, about seventy per cent of the estimated 1.1 billion people in poverty around the world live in rural areas and depend directly on the productivity of ecosystems for their livelihoods. Healthy ecosystems provide a diverse range of food sources and support entire agricultural systems, but their value to food security and sustainable livelihoods are often undervalued or ignored. There is an urgent need for increased financial investment for integrating ecosystem management with food security and poverty alleviation priorities. As the world's leaders worked towards a new international climate change agenda in Cancun, Mexico, 29 November-10 December 2010 (UNFCCC COP16), it was clear that without a deep and decisive post-2012 agreement and major concerted effort to reduce the food crisis,
\end{abstract}


the Millennium Development Goals will not be attained. Political commitment at the highest level will be needed to raise the profile of ecosystems on the global food agenda. It is recommended that full recognition and promotion be given of the linkages between healthy, protected ecosystems and global food security; that sufficient resources be allocated for improved ecosystem valuation, protection, management and restoration; and that ecosystem management be integrated in climate change and food security portfolios. We will not be able to feed the world and eradicate extreme poverty, if we do not protect our valuable ecosystems and biodiversity.

Keywords: food security; climate change; ecosystem management; ecosystem services; biodiversity; Millennium Development Goals; poverty

\section{Introduction}

The aim of this paper is to stimulate debate on the role of ecosystems in achieving food security, and to provide some direction and recommendations on how ecosystem management can contribute to the solutions we need for multiple problems. We take a mixture of perspectives, from practical measures at the ground level to philosophical and conceptual overviews. Central to every level is the stance that ecosystems and the services they provide (e.g., food, climate regulation, freshwater supply, disaster risk reduction such as coastal protection against storm surges by mangroves) are the fundamental units of life support on Earth. Ecosystem services can be seen as the processes by which ecological systems supply benefits to humans. Ecological systems are made up of complex interactions between biotic (communities of species, their genetic diversity, composition and interactions) and abiotic (soil, water, atmosphere and weather) components. The interactions of these include the functions of energy capture, the cycling and storage of water, carbon and nutrients. The Millennium Ecosystem Assessment (MEA) [1] grouped ecosystem services into four broad categories: provisioning, such as the production of food and water; regulating, including the control of climate and disease; supporting, such as photosynthesis, nutrient and water cycling and crop pollination; and cultural, covering spiritual and recreational benefits. Of these it is the supporting and regulating services that underpin the supply of the others. In respect of food security, it is necessary to consider all of these four broad categories and how they contribute to the supply of food. Ecosystem services do not provide food security per se, but underpin our ability to produce sufficient food resources. However, the MEA reported that ecosystem 'health' is declining (i.e., due to biodiversity and habitat loss, pollution, water and nutrient cycle changes and hence altered ecosystem functions), thus threatening their ability to provide the life supporting ecosystem services that we all rely on. These threats to ecosystem services, unsustainable food production systems and an imbalance in food distribution [2] pose a substantial risk to achieving food security. These together pose a further risk of societal de-stabilization.

The Millennium Development Goals (MDGs) [3] commit the world's nations to greatly improve food security, eradicate extreme poverty and reduce environmental degradation by the year 2015 . At the same time there is an increasing need to address other multiple social and environmental issues, 
such as the impacts on food security from globalization, population growth and changing food consumption patterns (i.e., dietary change with increasing demand for meat, poultry and dairy products in developing countries and consequences on water and nutrient utilization) [2]. About $70 \%$ of the world's poor live in rural areas, living on less than $\$ 2$ a day [4]. These people are most directly dependent on ecosystems for their nourishment, but have seen an increase in the number of hungry following a period when agriculture saw the Green Revolution focus on intensified production systems to increase yield. At the same time, trade liberalization policies that have not necessarily supported localized food production or recognized the contribution of small farms to economic development [5]. Compounding this is the need for societal and political adjustment to mitigate against, and adapt to climate change. Hence there is need for an approach that satisfies multiple objectives whilst ensuring the sustainable provision of the essential ecosystem services. These goals and objectives cannot be met solely through independent sectoral initiatives, as the problems and their solutions are closely inter-linked and contain complex trade-offs. Such trade-offs exist across a wide range of spatial and temporal scales and cut across many social and cultural considerations. They may include, for example, the maintenance of forest ecosystems to support water management, protection of biodiversity and prevention of greenhouse gas (GHG) emissions versus conversion to agricultural land for food production, or the extensification of livestock systems to reduce grazing pressure and allow vegetation regeneration versus cultural issues of wealth associated with livestock numbers. These reflect the frequent juxtaposition of objectives, such as producing more food with the same amount of agricultural land but with less energy and reduced fertilizer inputs (to reduce GHG emissions). Similarly, a single objective for ecosystem management, i.e., biodiversity conservation, may introduce trade-offs between different ecosystem services. This implies the need to be able to identify and quantify the trade-offs and develop a mechanism whereby they can be prioritized. On a global scale the trade-offs can be seen in the need to redress the imbalance in the equity in human wellbeing and distribution of wealth that would result in economic, social and cultural impacts.

Sustainably utilizing the world's ecosystems offers a highly cost effective multiple 'win-win' mechanism to achieve a food secure world and continued ecosystem services delivery (Section 4 provides more details on the cost-effectiveness of an ecosystems management approach). To do this, three key activities are essential:

1. Valuation - putting a monetary value on ecosystem services can be complex and controversial but the past 'invisibility' of nature's value to the economy has led to degradation [6]. Reversing this by developing valuation mechanisms that include ecosystem services and embedding them within economic and political processes will increase the probability of successfully preserving them.

2. Protection - coupled to the process of valuation, protection includes the activities by voluntary action, responses to incentives and support or the success of legislation and law and how it is enforced, coupled with monitoring and research.

3. Management - the degree to which an ecosystem's functions require human intervention in order to maintain ecosystem health (i.e., stakeholder agreed methods to ensure multiple objectives can be met). 
Ecosystem "health" refers to the state of an ecosystem in relation to its dynamism (process, fluxes and state of evolution), relatedness and hierarchy of processes (interactions between biotic and abiotic components driving process and fluxes operating at spatial scales ranging from the molecular to whole Earth, and temporal scales from seconds to millennia,) and creativity (or transformation of energy and cycling of nutrients through complex systems enabling self organization). This definition is based on five axioms of ecosystem management described by Norton [7] and interpretation by the authors from reviewer's comments. Norton's fifth axiom refers to the 'differential fragility' of ecosystems, that is the way they vary in their ability to absorb human based disruptions. Using these axioms as a framework, Costanza et al. [8] detail an operational definition of ecosystem health based on four characteristics of complex systems: sustainability, being a function of activity, organization and resilience. Thus "An ecosystem is healthy if it is active and maintains its organisation and autonomy over time and is resilient to stress [8]".

Healthy, fully functional ecosystems are better placed to achieve cost effective multiple objectives (ecosystem services), including progress towards food security under a changing climate, than degraded ones. They have underpinned all past and existing economic activity and will form the basis to achieve long-term economic sustainability (assuming societal development follows a sustainable pathway) by continuing to provide the essential services on which we depend. However, inadequate ecosystem protection coupled with a past lack of economic mechanisms that did not include the costs of environmental damage, has led to degradation and therefore a decline in ecosystem health and subsequent impact on ecosystem services, thus reducing the ability to feed substantial sections of human society.

Here ecosystem management can be defined as "an integrated process to conserve and improve ecosystem health that sustains ecosystem services for human well-being" (this is an aggregated definition based on [6-8]). Ecosystems are defined as encompassing all land and marine based natural and semi-natural systems, and associated land uses including conservation, livelihoods, pastoralism, agriculture, fishing and forestry. Climate change will alter the patterns of net primary production and change growing conditions for many crops and livestock systems [9]. Healthy ecosystems and their services provide opportunities for sustainable economic prosperity while providing defense against the negative effects of climate change $[6,10]$ through human adaptation and behavioral change, as opposed to a continuation of degradation (Figure 1).

Trade-offs between food security and ecosystem management are sometimes unavoidable (i.e., limiting the creation of new agricultural land), but there is far greater potential for synergies in achieving food security and ecosystem management than is generally recognized. Such synergies include biodiversity conservation, climate regulation and maintenance of water quality. As such the benefits can be seen to exist across multiple dimensions and the broad range of ecosystem services defined above. However, care is needed to ensure that the objectives of ecosystem management are balanced, as many situations will exist were the need to achieve food security (i.e., in places of poverty and food shortage), take priority over other objectives. Similarly, intensive agriculture can be seen as a form of ecosystem management and may be appropriate and necessary in some situations due to the benefits of scale of food production. 
Figure 1. Beating the vicious cycle of poverty, ecosystem degradation and climate change.

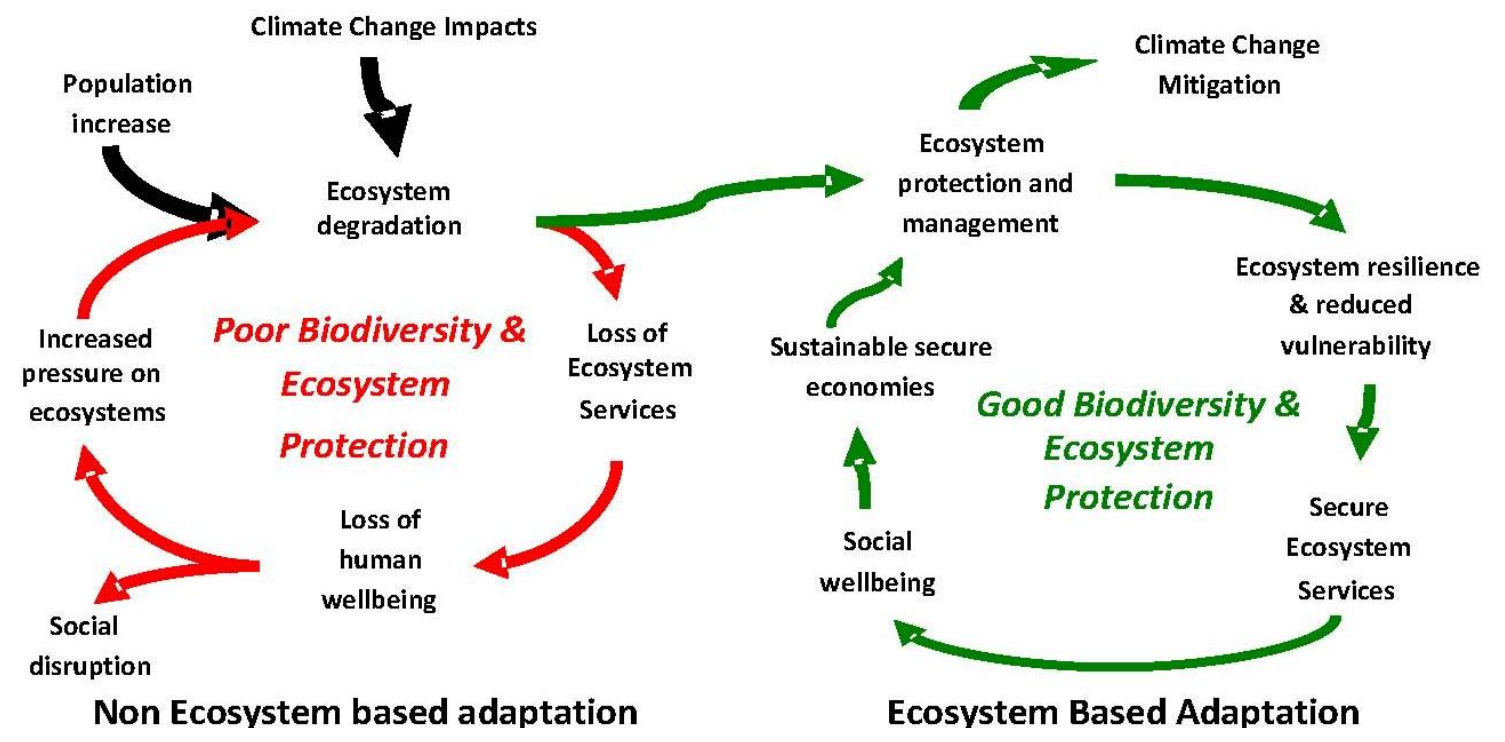

In the transformation to better biodiversity and ecosystem protection to reverse the cycle in Figure 1, an unprecedented effort will be required to adapt to changing biophysical conditions. These changes will be driven by altered rainfall and temperature regimes and interactions between them (i.e., dry or wet spell duration, altered evapotranspiration rates and changed soil moisture). Such altered conditions will result in changed ecosystem functions, hence novel approaches to adaptation will be required. An essential element in such adaptation is understanding ecosystem resilience. The Resilience Alliance [11] defines this as "The capacity of an ecosystem to tolerate disturbance without collapsing into a qualitatively different state that is controlled by a different set of processes. A resilient ecosystem can withstand shocks and rebuild itself when necessary". Maintaining biological diversity [12], at gene, species and community (functional groups of organisms) levels is an essential part of keeping within resilience tolerance limits. Considering resilient social systems in this definition gives 'socio-ecological systems' (SES) to reflect the interactions between people and their environment. Resilience theory [13] considers changes in the relationships between people and the environment which then enables a better understanding of how socio-ecological systems can adapt. Adaptive capacity considers the 'scope' that an SES has to maintain itself or retain its identity whilst transforming into an alternative form. Understanding the adaptive capacity of a SES helps identify thresholds (or tolerance ranges of components existing across multiple spatial and temporal scales) of a system in equilibrium under a given set of conditions (i.e., policy, economic, environmental) and therefore whether the thresholds of components, or the complete system, are exceeded when perturbations occur (i.e., from climate change).

Resilience is also scale related, both spatially and temporally. Easterling [14] contrasts short-term system resilience with long-term adaptive capacity. A system with short-term resilience can adapt its management to maintain existing functionality, absorbing impacts of varying magnitudes. Systems with long-term adaptive capacity are able to manage the process of altering their function and appearance to continue to deliver higher-level goals such as food supply or income for land managers, and landscape value. Thus adaptive capacity is required when change exceeds the short-term resilience of the system, but must seek to maintain long-term resilience without degrading system functions or 
reducing capital value (social, natural, human, financial and built/infrastructure). Hence identification of the limits of an ecosystem's resilience, the capacity to increase that resilience via changes to management systems and the consequences of such changes, make useful contributions to the assessment of climate change impacts on food security.

The MEA has clearly indicated the importance of ecosystem services in supporting food production; therefore healthy ecosystems are an essential element of food security $[1,15]$. Food security cannot be approached as a single objective. Rather, it requires a multiple objective approach where many ecosystem services continue to be delivered. Hence this paper aims to set out a compelling argument for establishing ecosystem-based management as an essential tool in national, regional and international strategies to achieve food security under a changing climate. It is in recognition of both the past market failures to adequately value the environment, and the risk that unchecked future economic pressures may be too great to enable a shift to a new sustainable paradigm. Fundamentally it sets out the need to establish ecosystem management as the foundation to enable food security and long-term economic and environmental sustainability, using these key messages:

- Ecosystems form the basis for all forms of life support, including provision of food, clean air and water, climate and disease regulation and many others.

- Biodiversity underpins the health of ecosystems.

- Appropriate ecosystem management forms the basis for sustainable food security and poverty alleviation [16]. Ecosystem management needs to operate in an integrated, synergistic way with other initiatives to enable achievement of shared multiple objectives that cut across temporal and spatial scales, economic sectors, cultures and national boundaries.

Scaling up local ecosystem-based initiatives is imperative and channeling resources and developing capacity at the local level, combined with supportive policy and institutional reform at higher levels could increase local people's food security, improve their health, reduce risks (i.e., in terms of disaster exposure through multiple food source supply of use of natural resources for protection), and will facilitate the potential to enable people to live more secure lives and so achieve the MDGs. The question of alternative possibilities needs to be posed. We can identify the approximate thresholds of resilience in some ecosystems (based on historic human land use caused ecosystem degradation) at some levels of spatial and temporal scale, and can estimate ecosystem responses to threats for others. However, it is difficult to be certain where we stand in proximity to thresholds of resilience, especially considering the complex mix of ecosystem interactions at multiple scales and their differential fragility [7], as the decline in ecosystem health is not likely to be linear. Therefore there is no logic to continue with the current situation of ecosystem health decline as this increases the risk of threshold excedence.

\section{Inter-Linkages between Food Security and Ecosystems}

The rural poor farmers depend heavily on natural ecosystems for their food security. Such farmers, often very poor in monetary terms, may have rich biodiversity at the farm level, with mixed cropping systems involving different types of annual and perennial crops, including trees and a diversity of farm animals. Such farmers need mechanisms of support, potentially in the form of payment for ecosystem services (PES) [17], to facilitate their role in maintaining ecosystem functions. This can also include 
carbon capture and the conservation of traditional varieties of crops that have important genetic resources. The rural poor rely directly on ecosystem services for clean and reliable local water supplies. Ecosystem degradation often results in water of both lower quality and quantity for people, crops and livestock, so reducing yields and is associated with higher risks of natural disaster [18].

International attention to ecosystems and biodiversity often focuses mainly on rare, endemic and endangered species and specific ecosystem services. Less widely recognized is the centrality of ecosystems to food security and livelihoods of everyone, but particularly the poor. Low-income rural people rely heavily on the direct consumption of wild foods, medicines and fuels, especially for meeting micronutrient and protein needs, particularly during periods of food shortages. Hunger itself reduces labor productivity, and the need to meet food needs during periods of food shortage can lead to depletion of household and community capital, compromising future potential [19].

An estimated 350 million [20] poor people rely on forests as safety-nets or for supplemental income. Farmers earn as much as 10 to $25 \%$ of household income from non-timber forest products. Bushmeat is the main source of animal protein in West Africa. The poor often harvest, process and sell wild plants and animals in order to buy food [21]. Sixty million poor people depend on herding in semi-arid rangelands which they share with large mammals and other wildlife. Thirty million low-income people earn their livelihoods primarily as fishers, twice the number of 30 years ago. The depletion of coastal fisheries thus has serious impacts on food security [22]. Wild plants are used in farming systems for fodder, fertilizer, packaging, fencing and genetic materials. Farmers rely on soil micro-organisms to maintain soil fertility and structure for crop production, and on wild species in natural ecological communities for crop pollination and pest and predator control. The rural poor also rely directly on ecosystem services for clean and regulated local water supplies.

Food insecurity threatens ecosystems when it leads to over-exploitation. Low farm productivity leads to depletion of soil and water resources, and pressure to clear additional land that serves as wildlife habitat. Some $40 \%$ of cropland in developing countries is estimated as being degraded [23]. Of more than 17,000 major protected areas, 45\% (accounting for one fifth of total protected area) are heavily used for agriculture, while many of the rest are islands in a sea of farms, pastures and production forests that are managed in ways incompatible for long-term species and ecosystem survival. Also, land use change, e.g. from native forest conversion to intensive systems (particularly palm oil, livestock systems and soya), deprives local people of traditional varied food sources, reduces biodiversity, climate regulation capacity and alters the economic basis for food provision on local and global scales [23].

\section{The Need for Balance}

In achieving the multiple goals of food security and maintaining ecosystem services, there is need for a balance between the many components, existing on multiple spatial and temporal scales that make up a socio-ecological system. For food security the two opposing sides are demand and supply. Population increase and on-going lifestyle expectations coupled with ecosystem degradation is likely to further upset what is already an imbalance [2]. If 'demand' were replaced by 'requirement' (based on equity of resource use) and 'supply' replaced by 'maintaining ecosystem productivity, regenerative capacity and resilience', then society would have better guidelines under how sustainable food systems 
would function. This requires more efficient use of food resources (less waste, reduction in over consumption etc.), which has additional benefits such as healthier diets. The probability of achieving a balance is greatly improved by protecting and appropriately managing ecosystems coupled with a fundamental shift in societal expectations and behaviors.

\section{Solutions That Are Cost Effective and Achieve Multiple Goals}

Protection and management of the diverse range of ecosystems within the world offer substantial cost effective solutions to address food security in a climate of change. The protection and management of the world's ecosystems also offers a highly cost effective multiple 'win-win' mechanism for climate change mitigation by enhancing sink capacity and limiting emissions beyond natural (ecosystem processes) levels. An advantage of an ecosystems-based management approach is that it can utilize existing knowledge, both scientific and indigenous, to realize the potential for food production, water conservation and bio-sequestration (carbon capture). Often these solutions can be rapidly deployable giving immediate positive effects [24]. An essential component within this concept is the need for training, education and information sharing.

The opportunities arising from greater investment in education and ecosystem management to counter issues of poverty and ecosystem degradation fully conforms with the shared vision of the UNFCCC, and objectives of the Convention on Biological Diversity [25], UN Convention to Combat Desertification [26] and Millennium Development Goals. International climate negotiations for a post-2012 agreement must incorporate the role of ecosystem management for ecosystem-based adaptation and mitigation. Such an approach must be adequately funded as the adoption of an ecosystems management approach at a global scale will serve as a 'safety net' against possible failures in the efforts to provide food security in the world.

\section{What Is the Ecosystems Approach?}

"An Ecosystems Approach is a strategy for the integrated management of land, water and living resources that promotes conservation and sustainable use in an equitable way [25]". It is a holistic way of dealing with natural resource management in an approach that recognizes the inter-connectivity between ecological, social-cultural, economic and institutional structures. Further to this, it is an approach driven by explicit goals, that is executed by policies, protocols, and practices, and made adaptable by monitoring and research based on our best understanding of the ecological interactions and processes necessary to sustain ecosystem composition, structure, and function [27]. The IUCN defines it as "a process that integrates ecological, socio-economic, and institutional factors into comprehensive analysis and action in order to sustain and enhance the quality of the ecosystem to meet current and future needs" [28].

The central goal of ecosystem management is sustainability, where the emphasis is on delivering ecosystems services for current use without compromising the ability to provide them in the future. A fundamental aspect of this is the need to protect sources of resources (ecosystems) [29]. To use a banking analogy, traditional economic approaches have been living off nature's capital, whereas a sustainable economic model based on ecosystem management is an attempt to live off nature's interest. This reflects the need to shift away from resource management towards ecosystem management. 
Central to this is that biodiversity is the key to supporting resilient, productive and healthy functioning ecosystems and therefore underpins the provision of ecosystems services [1,6]. For example, the number, kinds and traits of species present determine the organismal traits that influence ecosystem processes, so mediating energy and material fluxes directly or altering abiotic conditions (i.e., limiting resources, disturbance and climate) that regulate process rates [30]. Therefore any reduction in species (or diversity at any organizational level) is likely to unbalance the energy and material fluxes and so de-stabilize resilience. An ecosystems approach seeks to ensure that balance is maintained and resilience remains stable.

It must be stressed that ecosystem management is not a single concept that can be applied to all ecosystems together. Instead it is a concept that, for successful practical management application, must be developed and tailored to suit individual ecosystem and societal resource use requirements (governed by the relevant goals, policies, protocols and practices). A protocol within ecosystem management is to use risk assessment frameworks, considering the climatic hazards, exposure, sensitivity and adaptive capacity of biophysical and socio-economic systems, and identify adaptation responses that can minimize potential risks. Whilst ecosystem management can be tailored to 'local solutions' they can work towards shared goals at the global level, to meet 'local needs within global level objectives'. Overall, ecosystem management, when applied at the global scale is as much an ethos as a scientific concept. Ecosystem management is not a rejection of an anthropocentric for a totally biocentric worldview. Rather, it is management that acknowledges the importance of human needs while at the same time confronting the reality that the capacity of our world to meet those needs in perpetuity has limits and depends on the functioning of ecosystems [31] that have thresholds of resilience.

\section{People in the Balance}

There is a need to balance many opposing demands. The human population is expanding and the expectation of an increasing number of people is for living standard improvement and material gain, placing additional demands on resource use. To achieve food security (and all other aspects of sustainability) there needs to be a shift in human expectations, aspirations and behavior and immediate resource use. At the same time it must be recognized that poverty alleviation is a primary objective. The aspirations of the poor need to be respected and support given to realize them, especially in cases were impoverished people cause ecosystem degradation in their struggle for survival using scarce resources. This is often due to a lack of power and governance structures that would enable them to reverse the decline [32]. On the other hand, excessive resource consumption needs to be reduced in order to achieve suitable levels of equity. Taking Norton's fifth axiom of ecosystem management, of 'differential fragility', and that ecosystems provide the essential basics for livelihood provision particularly for the poor, excessive resource demands from some countries (which may have relatively healthy ecosystems due to investment and protection) cause degradation in fragile ecosystems beyond their own borders (the impacts of climate change, high levels of water usage for goods production-virtual water [33], and conversion of forest to palm oil for biofuels [34] are examples). Hence fragile ecosystems that support local people are degraded as a result of economic behavior in other parts of the world. This implies that the ecosystem management approach must be holistic 
and mainstreamed within economic thinking, balancing trade-offs across multiple spatial and economic scales.

Central to many of the solutions in terms of practical application, is the need to achieve behavioral change through supportive and enabling policies that redress the current imbalance in trade-offs. Fundamentally, people adopt new ways of doing things if:

a. There is an economic benefit.

b. There is a clear rationale as to why change is needed.

Thus in making effective change there is need for new economic and policy systems, adjusting the balance of power to empower communities to manage the ecosystems they depend on, and investment in education and information services across all communities on the rationale for protecting ecosystems, as well as practical ecosystem protection and management. Fundamental to all these, across all sections of human society, is the need for a collective, equitable response that works towards the shared goals of sustainability and security. Such a response will require an elemental shift in societal attitudes towards the importance of our environment and its role in sustaining life which can then translate to changed behaviors [35].

\section{Priority Areas of Action}

Ecosystem degradation including biodiversity loss, pollution, erosion and altered water availability and are the most serious threats to the local, national and international scales of food provision. To address this:

Firstly, strengthening ecosystems governance and institutions at local and national levels is a pre-condition for any effective policy response to food security.

Secondly, it should be explicitly recognized that one of the main drivers for ecosystem degradation is economic, and that the past lack of ecosystem valuation has been a market failure, e.g., forests are destroyed because it is more profitable in the short term to use land for other purposes, or the environmental cost of water use in goods production is not included in the purchase cost to the consumer [36]. Therefore an effective policy has to reward the long-term value of the services provided by ecosystems above that of the short term gain. There is need therefore for an economic mechanism that fully values ecosystems and the services they provide.

Thirdly, if change is to be designed and implemented properly, it must be based on high quality information. Existing ecosystem monitoring and assessment programs are either incomplete or only partially integrated. The money spent on ecosystems research and monitoring does not reflect the true value of the services that ecosystems provide to the global economy. More support is required for science to provide the basis for a comprehensive science-based management approach to guide policy decisions and monitor implementation. 


\section{Required Complementary Strategies}

To address the issues detailed here, we have identified four complementary strategies. These are based on the recognition that single, isolated approaches are unlikely to achieve the level of change required in order to meet the challenges we face. Without all four of these strategies working together, it can be argued that global scale societal adaptation will be unable to adapt in a co-ordinated and effective way. There is a dependency between these strategies, hence there is need for a unifying concept that serves as the medium for integration. Ecosystems and their role in supporting human society can serve as that medium on which integration is based within such a unifying concept, if we recognize their significance, fragility and resilience thresholds. The four strategies are:

1. The need for Political commitment. There must be a sense of urgency to raise the profile of ecosystems in food and climate change policy settings at local, national and international levels.

2. Greater levels of Investment. There must be explicit inclusion of investments related to ecosystem management and ecosystem protection. The scale of investment must be commensurate with the value of the ecosystems services.

3. Development of Incentives and policies. There must be a deliberate focus on introducing incentives to ease existing pressures on ecosystems and support changes that increase environmental resilience and resource sustainability, including incentives for increased land and water protection.

4. Provision of Information. There must be a solid commitment to establish comprehensive information and foster closer links between ecosystem management, climate-change mitigation and adaptation, as well as between science, education, economics, politics and policy. In addition, there must be increased information sharing between countries, including North-South and South-South exchanges to ensure the flow of new ideas and knowledge, and to have mutual benefit of learning by experience of implementation of new policies and practices (i.e., what contributes to success or failure of PES, the uptake of new practices or best institutional structures and methods of governance).

To effect the changes required, actions are necessary across a broad range of institutes, organizations, groups, communities and individuals. Across society, collective responsible actions are needed to adopt sustainable behaviors such as ensuring minimal waste and reduction of excessive resource consumption. Institutional reform and improved empowerment through equitable governance must operate within the targets of achieving protected, healthy ecosystems whilst optimizing human wellbeing. The key challenge is getting governments to act. Whilst the quality of science supporting the evidence for ecosystem degradation has improved, there remains an imbalance in political response to this new information. Increasingly politicians are looking to the science community for solutions. The following are seen as some of the fundamental solutions in support of the above four complementary strategies:

- Addressing market failures through appropriate valuation of ecosystems and the services they provide [37]. A fundamental shift is required away from valuing private goods and services towards valuing public benefits of ecosystems where the application of ethical principles for sustainability plays a central role, including those values and principles articulated in the Rio Declaration and the Earth Charter (All strategies). 
- Continue development of funding mechanisms to support inclusion of ecosystem-based solutions for food security adaptation, capacity building and innovation [24]. (Strategy 2-Investment).

- Greater integration between knowledge of economics, ecosystems and their management at governmental level, recognizing the limitations on human activity posed by ecosystem capacity. (Strategy 1-Political commitment). Such integration includes;

- More equitable balance within government advisory departments between traditional views on economics (no limit to substitution thus less concern for value of ecosystem services and such externalities can be internalized into commodity selling price) and ecological economics (working with vulnerable and finite resources that underpin economic activity) within the knowledge capital of governments and financial institutions.

- Inclusion of natural capital in national accounting systems.

- Foster approaches of 'local solutions for global problems', and 'meeting local needs within global level objectives'. This requires a global over-arching ethos of conservation, sustainable resource use based economies and knowledge of ecosystem functions. This needs to be coupled to issues of property ownership, access and resource utilization rights. Ill-defined property rights and the fact that many of the world's poor and food insecure live and operate within commons regimes or have no land tenure, and where certain users cannot be excluded from common land are important factors that need to be considered. (Strategy 3-Incentives and policies).

- Promote public education and facilitate behavioral change. People need to know the consequences of their actions in order to know how to make informed decisions affecting their actions, lifestyles and consumer choices. Society also needs to be better aware of why governments aim to change individuals' behavior, through better up-dates on the state of the climate and ecosystem health. (Strategy 4-Information).

- Guaranteed funding for environmental protection. To ensure appropriate protection of ecosystems and services, a secured funding mechanism is needed to insure against variation in the global economy and sporadic expenditure. It must provide sustainable long-term support for ecosystem protection and restoration efforts and be tied to local communities following sustainable practices of resource utilization, rather than supporting unsustainable practices. (Strategy 2 - Investment).

- Scale the strategy appropriately. For example, in Togo through a UNEP/UNDP Programme called Climate Change Adaptation and Development (CC DARE) [38], using small-scale fiscal stimulus action, a small dam was renovated for harvesting rainwater and has improved access to water for the local communities and also expanded rural livelihood activities, e.g., market gardening, brick construction and fisheries, besides uses for domestic and agro-pastoral consumption. The co-benefits of the project action in having year-round water supply to the surrounding ecosystem include natural regeneration and restoration of biodiversity, serving as medicinal products for the households and dietary supplements for local communities.

The merits of the small-scale approaches are evident in the engagement of local users in ecosystems management, keeping the implementation process simple, and thus making them more efficient, effective, equitable, and environmentally sustainable than past top-down practices. The use of practical interventions in the form of projects has been shown to play a crucial role in unpacking complex concepts, building capacity, and developing appropriate tools for up-scaling the interventions to a local 
government or national level. Experience shows that small but well-timed and targeted interventions can have significant impacts in, for example, moving policies forward or spurring development of larger efforts. There is also need for top-down approaches that complement small-scale strategies. If successfully executed, such interventions have the potential to inform polices and contribute information and data valuable for the assessment processes. This is vital as we need science based impact measures to know how our actions affect nature and the services it can provide.

Responsibility for these changes exists across all sections of society. It thus becomes an issue of the sequence by which events lead from impact to action. A logical argument would go that it is the responsibility of governments to act on the evidence provided by science. However, governments respond to their perceptions of society's reactions to policies and performance. At the same time governments are constrained by many factors including financial limitations and global economic structures, hence policies designed to ensure ecosystem protection may be seen by society as costly in financial terms and detrimental to economic wellbeing. This raises the question of is it an individual's responsibility to effect change and influence the actions of governments? For many people this is either not an option or there is very limited capacity. Even where it is possible (and also not), there is still considerable doubt amongst society as to how seriousness the situation is, and where the environmental issue rates in relation to other issues that are seen to be more immediate. The solutions required therefore encompass a wide range of responsibilities and issues including education and the dissemination of scientific information. Given this complex situation and the associated risk of inaction, it can be argued that the overall solution is as much about developing the ethos of ecosystem protection and management across the whole of society to facilitate change, as it is about developing specific mechanisms.

\section{Recommendation for Securing Provisioning Services}

The following points detail recommendations centered around practical steps towards securing provisioning services from ecosystems at the local to regional scale.

1. Develop ecosystem reserves and protected areas as community "safety-nets". Communities can establish, enrich or conserve special ecosystems/biodiversity reserves. These can be designed and managed to protect wild species that serve as "safety-nets" for the poor in times of food scarcity, as well as ecosystem services of local importance. However, this calls into question the availability of land for such purposes, hence such an approach has to be integrated with the multiple objectives for land use, suitability for purposes and tenure.

2. Strengthen local communities' ownership and rights of use of natural resources, coupled with monitoring and education programs. In some countries, devolution of state forest land to local communities, as private individual or group holdings, has already doubled in the past 15 years and is continuing [39]. Priority areas for reform can be those indigenous and other local managed lands that are already being well-managed for biodiversity conservation and other ecosystem services, and where communities have organized to defend their resources from outside encroachment.

3. Pay rural communities for the ecosystem services they provide. New approaches are being developed to provide financial incentives for stakeholders to manage their resources in ways that preserve ecosystem services and biodiversity. These include special tax incentives and direct payments 
to farmers and communities for keeping land out of production, practicing eco-agriculture, or combining with forest restoration to give watershed protection, carbon sequestration, landscape beauty and biodiversity protection (i.e., FONAFIFO in Costa Rica [40]). Several hundred PES systems are already underway around the world for upland watershed management, biodiversity conservation, carbon emission offsets, and landscape beauty. Low-income rural communities that own or manage high-value or high-impact natural resources can benefit from such payments, where their rights are respected.

4. Support the development and adoption of eco-agriculture. Investment to increase crop, livestock, and forest and fisheries productivity is essential in many low-income rural regions. But new eco-agriculture approaches can be used that at the same time conserve or enhance natural ecosystems. Eco-agriculture strategies include using the spaces in and around productive areas for habitat networks (connectivity conservation), while also improving the habitat quality of productive areas themselves by reducing agro-chemical pollution, modifying water, soil and vegetation management, or by modifying farming systems to mimic natural ecosystems. To develop, promote and support eco-agriculture innovations will require increased research and policy changes, including the re-building of technical assistance services that support producers in managing both agricultural and natural resources.

5. Reform governance systems for local resource management. To protect and restore habitats and watersheds will require coordination and planning at the community and landscape scale. Devolution of significant real authority and budgets for land use planning to the local level is essential, with adequate access to specialized expertise. Responsibility for this must be shared between the respective communities, local and national governments with support from a range of stakeholders. Participatory planning processes can facilitate negotiations among these stakeholders, including farmers, conservationists, agri-business, local residents and other groups that include food security, biodiversity conservation and economic development objectives.

6. Promote partnerships among key stakeholders in rural landscapes. Partnerships can be developed that actively link farmers, conservationists, policymakers and natural resource managers from different parts of the world to share information, successful strategies and expertise.

7. Recognize, promote and value protected areas as a storehouse of wild food relatives. As the diversity of wild and cultivated crops deteriorate, protected wild food relatives will only increase in value in safeguarding the future of our food.

\section{Conclusions}

In this paper we have argued that ecosystems play an essential role in enhancing food security. Ecosystems supply the fundamental units of life support, by providing ecosystem services that enable us to produce or utilize food and water. They also provide clean air and climate regulation, shelter and medicines, cultural and aesthetic wellbeing, and can have a vital role in disaster risk reduction. These ecosystem services are however under increasing pressure and threat of further degradation. As climate change and other pressures bring to bear increasing stresses, we need to ensure that ecosystems do not continue to degrade. Instead we must ensure that they remain healthy and fully functional in order to provide the vital ecosystem services we rely on. We should therefore seek to protect, restore and improve ecosystems, particularly those that have been most degraded. 
Given this vital role that ecosystems play in sustaining a growing human society, their current rate of degradation and the emerging threats of climate change, it is doubtful that existing approaches to integrating environmental concerns with economic policy development will be sufficient by themselves to tackle the problems we face [41]. Instead, whilst the ecosystem-based adaptation approach is not a panacea for all problems, it is one that when integrated with other strategies working towards the same goals (climate regulation, poverty alleviation and sustainability), forms the foundation for a successful integrated strategy for food, water and ultimately societal security. An ecosystem based approach will serve as the foundation in developing a 'Green Economy' [37,42,43]. Ecosystem management acknowledges the importance of human needs while at the same time confronting the reality that the capacity of our world to meet those needs in perpetuity has limits and depends on the functioning of ecosystems.

The greatest challenge for governments and global leaders is to adjust national and international economies in line with climate change mitigation and adaptation efforts whilst maintaining ecosystem health and financial stability. Use of the life support services of ecosystems will help economies, financial institutions and societal behavior to make those adjustments in progressing towards a food secure, green low carbon economy, but only if ecosystem health is maintained. Fundamentally, ecosystems form the foundation of life support and hence require appropriate protection and management at a level commensurate with their true value in supporting the global economy. It is vital therefore that the issue of ecosystem management be integrated with other measures to address food security and climate change. It is recommended that an ecosystems approach becomes centrally embedded within local, national, regional and international level planning and policy making to ensure ecosystem health to give a food secured world and in achieving the Millennium Development Goals.

\section{References}

1. Millennium Ecosystem Assessment (MEA). Ecosystems and Human Well-Being: Synthesis; Island Press: Washington, DC, USA, 2005; p. 155.

2. Foresight. The Future of Food and Farming. Final Project Report. The Government Office for Science: London, UK, 2011.

3. Millennium Development Goals. Available online: http://www.un.org/millenniumgoals/ (accessed on 21 October 2010).

4. Developing World Fact sheet. Available online: http://www.ifad.org/rpr2011/media/kit/factsheet_e.pdf (accessed on 21 October 2010).

5. Fosset, P. The multiple functions and benefits of small farm agriculture in the context of global trade negotiations. Development 2000, 43, 77-82.

6. TEEB. The Economics of Ecosystems and Biodiversity: Mainstreaming the Economics of Nature: A Synthesis of the Approach, Conclusions and Recommendations of TEEB. The TEEB Synthesis Report, Nagoya, Japan, 20 October 2010.

7. Norton, B.G. Toward Unity Among Environmentalists; Oxford University Press: New York, NY, USA, 1991.

8. Ecosystem Health: New Goals for Environmental Management; Costanza, R., Norton, B.G., Hakell, B., Eds.; Island Press: Washington, DC, USA, 1992. 
9. IPCC. Climate Change 2007: Impacts, Adaptation and Vulnerability. Contribution of Working Group II to the Fourth Assessment Report of the Intergovernmental Panel on Climate Change. Parry, M.L., Canziani, O.F., Palutikof, J.P., van Linden, P.J., Hanson, C.E., Eds.; Cambridge University Press: Cambridge, UK, 2007; p. 976.

10. Mackey, B. Connecting Biodiversity and Climate Change Mitigation and Adaptation. Report of the Second Ad Hoc Technical Expert Group on Biodiversity and Climate Change. CBD Technical Series No. 41. Secretariat of the Convention on Biological Diversity: Montreal, Canada, 11 September 2009; ISBN: 92-9225-134-1.

11. Resilience Alliance 2011. Available online: http://www.resalliance.org/index.php/resilience (accessed on 25 April 2011).

12. Thompson, I.; Mackey, B.; McNulty, S.; Mosseler, A. Forest Resilience, Biodiversity, and Climate Change. A Synthesis of the Biodiversity/Resilience/Stability Relationship in Forest Ecosystems; Secretariat of the Convention on Biological Diversity: Montreal, Canada, 2009; Technical Series No. 43, p. 67.

13. Holling, C.S.; Gunderson, L.H. Resilience and adaptive cycles. In Panarchy; Holling, C.S., Ed.; Island Press: Washington, DC, USA, 2002.

14. Easterling, W.E. Adapting North American agriculture to climate change in review. Agr. Forest Meteorol. 1996, 80, 1-53.

15. Millenium Ecosystem Assessment. Available online: http://www.millenniumassessment.org/ (accessed on 21 October 2010).

16. The Environmental Food Crisis: the Environment's Role in Averting Future Food Crises; Nellerman, C.B., MacDevette, M., Manders, T., Eickhout, B., Svilhus, B., Prins, A.G., Kaltenborn, B.P., Eds.; UNEP: Washington, DC, USA, 2009.

17. Payment for Ecosystem Services. Available online: http://en.wikipedia.org/wiki/Payment_for_ ecosystem_services (accessed on 21 October 2010).

18. McNeely, J.A.; Scherr, S.J. Eco-Agriculture: Strategies to Feed the World and Save Wild Biodiversity; Island Press: Washington, DC, USA, 2002.

19. FAO. The State of Food Insecurity in the World: 2002; Food and Agriculture Organization of the United Nations: Rome, Italy, 2002.

20. Scherr, S.J.; White, A.; Kaimowitz, D. A New Agenda for Forest Conservation and Poverty Alleviation: Making Markets Work for Low-Income Producers; Forest Trends and the Centre for International Forestry Research: Washington, DC, USA, 2003.

21. Scherr, S.J.; McNeely, J.A. Reconciling Agriculture and Biodiversity: Policy and Research Challenges of "Eco-agriculture"; Equator Initiative: Arlington, VA, USA, 2002.

22. Burke, L.; Kura, Y.; Kassem, K.; Spalding, M.; Revenga, C.; McAllister, D. Pilot Analysis of Global Ecosystems: Coastal Ecosystems; World Resources Institute: Washington, DC, USA, 2000.

23. The Environmental Food Crises-The Environment's Role in Averting Future Food Crises; Nelleman, C., MacDevette, M., Manders, T., Eickhout, B., Svilhus, B., Prins, A.G., Kaltenborn, B.P., Eds.; A UNEP rapid response assessment. United Nations Environmental Programme, GRID-Arendal: Washington, DC, USA, 2009.

24. The World Bank. Convenient Solutions to an Inconvenient Truth: Ecosystem-Based Approaches to Climate Change; The World Bank: Washington, DC, USA, 2009. 
25. United Nations Convention on Biological Diversity. 2000. Available online: http://www.cbd.int/ (accessed on 21 October 2010).

26. United Nations Convention on Biological Diversity. 2011. Available online: http://www.unccd.int/ (accessed on 21 October 2010).

27. Christensen, N.L.; Bartuska, A.M.; Brown, J.H.; Carpenter, S.; D’Antonio, C.; Francis, R.; Franklin, J.F.; MacMahon, J.A.; Noss, R.F.; Parsons, D.J.; Peterson, C.H.; Turner, M.G.; Woodmansee, R.G. The report of the ecological society of america committee on the scientific basis for ecosystem management. Ecol. Appl. 1996, 6, 665-691.

28. IUCN Homepage. Available online: http://www.iucn.org/about/union/commissions/cem/cem_about/ (accessed on 21 October 2010).

29. Grumbine, R.E. Reflections on "What is Ecosystem management". Conserv. Biol. 1997, 11, $41-47$.

30. Chapin III, F.S.; Zavaleta, E.S.; Eviner, V.T.; Naylor, R.L.; Vitousek, P.M.; Reynolds, H.L.; Hooper, D.U.; Lavorel, S.; Sala, O.E.; Hobbie, S.E.; Mack, M.C.; Díaz, S. Consequences of changing biodiversity. Nature 2000, 405, 234-242.

31. Christensen, N.L.; Bartuska, A.M.; Brown, J.H.; Carpenter, S.; D'Antonio, C.; Francis, R.; Franklin, J.F.; MacMahon, J.A.; Noss, R.F.; Parsons, D.J.; Peterson, C.H.; Turner, M.G.; Woodmansee, R.G. The report of the ecological society of america committee on the scientific basis for ecosystem management. Ecol. Appl. 1996, 6, 665-691.

32. Grimble, R.; Cardoso, C.; Omar-Chowdhury, S. Poor People and the Environment: Issues and Linkages; Policy Series 16. Natural Resources Institute: Chatham, UK, 2002.

33. Allan, J.A. Virtual water-The water, food and trade nexus: Useful concept or misleading metaphor? Water Int. 2003, 28, 106-113.

34. UNEP Year Book; United Nations Environment Programme: Washington, DC, USA, 2010. Available online: http://www.unep.org/yearbook/2010/ (accessed on 21 October 2010).

35. Nkem, J.; Munang, R.; Jallow, B. Decentralizing solutions for rural water supply under climate impacts in Africa. Environment 2011, 53, 15-17.

36. Hoekstra, A.Y.; Chapagain, A.K. Globalization of Water: Sharing the Planet's Freshwater Resources; Blackwell Publishing: Malden, MA, USA, 2008.

37. TEEB. The Economics of Ecosystems and Biodiversity for National and International Policy Makers. TEEB Report, Brussels, Belgium, 13 November 2009.

38. Climate Change Adaptation and Development Initiative; United Nations Environment Programme: Washington, DC, USA, 2009. Available online: http://ccdare.org/ (accessed on 21 October 2010).

39. Capistrano, D. Decentralization and forest governance in Asia and the Pacific: Trends, lessons and continuing challenges. In Lessons from Forest Decentralization: Money, Justice and the Quest for Good Governance in Asia-Pacific; Colfer, C.J.P., Dahal, G.R., Capistrano, D., Eds.; Earthscan: London, UK, 2008; Chapter 13.

40. The National Forestry Financing Fund. Available online: http://www.fonafifo.com/english.html (accessed on 21 October 2010). 
41. Mumba, M.; Munang, R.; Rivington, M. Ecosystem management: The need to adopt a different approach under a changing climate. Response to Key Question Four: Must We Fundamentally Change Course to Conserve Ecosystems in a Changing Climate? World Resources Report, Cancun, Mexico, 2010. Available online: http://www.worldresourcesreport.org/expertperspectives/question-four (accessed on 21 October 2010).

42. Green Economy. UNEP's Ground-Breaking Report. United Nations Environment Programme: Washington, DC, USA, 2010. Available online: http://www.unep.org/greeneconomy/ (accessed on 21 October 2010).

43. Earth Summit. Stakeholder Forum: London, UK, 2010. Available online: http://www.earthsummit2012.org/ (accessed on 21 October 2010).

(C) 2011 by the authors; licensee MDPI, Basel, Switzerland. This article is an open access article distributed under the terms and conditions of the Creative Commons Attribution license (http://creativecommons.org/licenses/by/3.0/). 